\title{
Discuss the application of innovative service thinking in the design of qualia goods---Take the case of The One South Garden as an example
}

\author{
Wei $\mathrm{Bi}^{1.2 \cdot, J u} \mathrm{Wu}^{2}$ and Rungtai Lin ${ }^{2}$ \\ ${ }^{1}$ School of Jewellery, West Yunnan University of Applied Sciences, \\ ${ }^{2}$ Graduate School of Creative Industry Design, National Taiwan University of Arts
}

\begin{abstract}
In recent years, aesthetics is rising rapidly accompanied by the knowledge economy, and the government has also begun to put forth effort to carry out the concept of designing service industry chain, and its emphasis is on how to add value of design creativity in culture, achieve design industry, and form an aesthetic economy. The creative life industry refers to the "core knowledge" that integrates the life industry with creativity, providing life industry of "deep experience" and "high-quality aesthetic feeling". It emphasizes that because of adapting to the trend of cultural economy and experience economy, it shall take customer experience as the core, through "products", "services", "activities" and "fields" to satisfy the consumer's life proposition, create a unique taste of life, and form a life style recognized by the consumer and through innovative service thinking to attract consumers' attention and maintain consumers' deep moving. The creative life industry has the characteristics of cultural life and industrial culture. Facing the trend of experience economy, it is an important issue to be discussed in depth how the creative life industry uses "experience" to develop customer experience values, thereby create economic benefits and deeply cultivate cultural values. Therefore, this study discusses how to use "perceptual fields" and "qualia products" through the case of The One South Park to strengthen and deeply cultivate the moving of consumers, to simulate how to transform from an invisible qualia experience into a tangible creative product, and to provide a reference for enterprises that want to enhance their industrial competitiveness with a qualia experience.
\end{abstract}

\section{Preface}

In recent years, the decline of traditional industries has made it necessary for us to change our thinking and discuss out a new mode of industrial thinking. If the traditional industry wants to have a certain status in the future, it must have its own cultural brand. In addition to the promotion of technology, it must also have both creative design and humanistic care. How to transform "culture" into "creativity" and add value of products "design", that is, how does "cultural creativity" "add value of design". It will be the primary topic for Taiwan to develop a cultural and creative industry and enhance the competitiveness of the design industry in the future. The economic development of Taiwan has gradually evolved from "manufacturing economy" to "knowledge economy" and "creative economy", and it has begun to think about how to go from "professional subcontractor" to "brand" or "design" which has higher value.

At present, many industries are in the transitional period and their focus of the economy has gradually shifted from the traditional manufacturing industry to the service industry. And the goods purchased by consumers are no longer just the entities of commodities themselves, furthermore, it is further extended to the intangible meaning and identity behind the goods. Therefore, a product that is only material and meaningless will no longer attract the attention of consumers. Only goods with "style" and "aesthetics" can outshine others; that is, generally so-called "taste" goods. It is also because design and aesthetics have gradually become an important element of the commodity itself, and matched with its own "quality" and the "brand" element that can enhance the added value, and then the "Qualia" is gradually focused and constructed. Through the combination of three aspects of the "taste" of design, aesthetics perspectives, the "quality" of manufacturing perspectives, and "branding" of marketing perspectives, it can create "Qualia" goods that make consumers feel happy, unique, and happy, which is the direction of service innovation design and development in the future.

In recent years, aesthetics is rising rapidly accompanied by the knowledge economy. The government has actively designed the concept of industrial chain to set up a plan for the development of a cultural and creative industry. The emphasis of the entire cultural and creative industry plan is on how cultures add 
value to "design creativity" to become profitable "cultural businesses", and then to form an "esthetic economy". Today, enterprises face the impact of "economic globalization". How to combine culture to develop their design creativity and face the challenge of the wave of "market globalization" with "design in geochemistry" to create product features. On the other hand, the concept of "consumer-centric" service innovation design plays a key role in aesthetics economy and experience design. It is also the primary topic for Taiwan to develop its creative life industry and enhance the competitiveness of the design industry in the future.

The creative life industry has the characteristics of cultural life and industrial culture. Facing the trend of experience economy, it is an important issue worth discussing deeply how the creative life industry uses "experience" to develop customer experience values, thereby creating economic benefits and deeply cultivating cultural values. This study combines experience-related theories and models and proposes the "qualia experience model". And it discusses how to use "sensitive fields", "moving experience" and "qualia products" through the case of The One South Garden to strengthen and deeply cultivate the moving of consumers. Under the thinking of service innovation design, it provides a reference for the enterprise to move toward the qualia experience economy, and serves as an aim to fully enhance the competitiveness of small and medium-sized enterprises.

\section{Discussion of literature}

Lin Rongtai proposes the "integration of cultural, aesthetic economy contributed to the aesthetic design of new industries" and hopes that through the introduction of culture, technology, and aesthetics, the cultural and creative industries are transformed into a creative life industry based on "service innovation". According to the various industries defined by the Cultural and Creative Industries Promotion Group in Economic Ministry, the definition of the creative life industry refers to "integrating the core knowledge of the life industry with creativity to provide an industry with deep experience and high quality aesthetic feeling". The main contents include three major elements of "core knowledge", "deep experience" and "high quality beauty". The characteristics of the life creative industries are based on existing industries and framed on the use of life culture, aesthetics, and creativity. Through the design of creative life and providing quality living experiences, the business model of integrated service innovation and design has been developed. The relevant literature of experiences, perceptual field and qualia goods we have discussed are as follows:

\subsection{Experience economy}

Pine II and Gilmore put forward the theory of "experience economy" and regard "experience" as the output of economic type from the value produced by economic activity. It is also an added value of tradable money and goods or commodity. Pine II and Gilmore have further divided the value of economic activity output into four types of goods: commodities, goods, services, and experience from the consumption experience. Li Renfang has the following instructions in the preface to the Chinese version of the book, for the enterprise managers: "If you charge for raw materials, you are a primary product company. If you charge for tangible product, you are a commodity company. If you charge for your activity, you are the service company. If you charge for the time you spend with your customers, you are experience company."

With the rise of experience economy and the transformation of consumption patterns, the symbolic meaning of consumption has evolved from satisfying the basic usage needs to becoming a reflection of consumers' pursuit of self-style identity and life value. Therefore, the core value of future products has changed from the past "use" satisfaction to the "user" pleasure, which is the so-called "From Use to User", and from the manifestation of "function" in the past to the "feeling" experience of users, which is the so-called "From Function to Feeling". Finally, the value of the product has also changed from the pursuit of "hi-tech" quality to the appeal the taste of "hi-touch", which is the called "From Hi-tech to Hi-touch". Therefore, the intangible perceptual value behind the product gradually exceeds the use value of the goods and becomes a key factor influencing consumers' purchase behavior (Lin Rongtai, Lin Boxian, 2009).

\subsection{Perceptual field}

Space is a situation and a way of telling stories. From the display design of showcases to the design of large-scale playgrounds, that is a field that creates atmosphere through situational design. In the life style of new life ideas and experiencing new values, a type of leisure life through the field has already quietly entered the lives of Taiwan consumers. From the IKEA of the Metropolis Shopping Centre to the lavender forests in the outskirts of the country, or The One South Garden, where all show the experience charm created by the field. Imagine that a couple, who hold their hands with each other, walk in the field created by IKEA and sit on the IKEA sofa in the living room to feel the warmth of the home. Then they copy the product number with the imagination created by the field to the downstairs warehouse to find boxes of products. This is the situational experience that IKEA creates for the customer to build a home.

Many researchers have mentioned that through the creation of a physical environment, many clues can be provided to consumers. These suggestions have a big impact on customers' impressions. Bitner (1992) first defined the service field as "do effective service behavior in specific physical environment". Lin (2004) used the concept of gestalt psychology to discuss and explain how individuals obtain impressions from the service field, and produce emotional reactions. Therefore, whether it is a trendy or open display design, and consumers or visitors 
may want to bring home the IKEA consumer field setting situation, because its situation display has evoked the consumer's past experience, or some emotional factors. Therefore, how does the spatial field create to satisfy the customer's psychology and what kind of experience or image does the spatial field bring to the customer? From a perceptual engineering point of view, a successful emotional field includes three levels:

(1) Can the customer see (situational perception)?

(2) Can the customer understand (situational awareness)?

(3) Can the customer be moved (to change behavior)? In short, a successful emotional fields must attract customers through the design of the field, and then allow customers to feel the function of creating a situation, and finally, to achieve the purpose of moving the soul of the consumer. This is the main purpose of this study.

\subsection{Qualia goods}

The so-called "Qualia" is a kind of life meaning and emotional satisfaction, and it touches the deepest feelings in consumer's heart with a touching romance. Qualiagoodsor services extend on the basis of quality, constructuniqueness and increasethe added value of goods and services through the presentation of five qualias of perceptual value, namely, Attractiveness, Beauty, Creativity, Delicacy and Engineering, and then arousecustomer's spiritual joy and moving. What is the difference between qualiagoods and general industrial products? The design of general industrial products in the past focuses on "function" (use), but the design of qualiagoods in the future focuses on "people" (user). Qualiagoods pursue the aesthetic features of "art", and general industrial products pursue "standard" technical specifications, so the difference is that aesthetic features of "art" are the requirements for "people", while "standard" technical specificationsare the quality control of "objects".Qualia goods are the expression of "human nature", and general industrial products are the pursuit of "propertyof objects"; qualiagoods are the pursuit of sensibility, and general industrial products are the demand of "reason"; and qualiagoods focus on "story", and general industrial products pursue "rationality". We need some stories to embellish our lives, and good qualiagoods usually have a moving story, that's why qualiagoods touch people. The concept of qualiagoods is generally arranged as follows: science and technology is the basis of qualia goods, so pursue "perceptual science and technology"; human nature is the beginning of qualia products, so focuson "humanistic design"; and culture is the source of design thinking,so pursue "qualia creativity". Therefore, modern designers must integrate "perceptual science and technology" and "humanistic design" to create a humanized product and service environment with "qualia creativity".

\section{Research methodand framework}

This study is basically based on the research framework of "Integrate culture and aesthetic economy to promoteemerging industries of aesthetic design" proposed by Lin Rongtai.In terms of creative life industry, design can be divided into four assessment dimensions: core knowledge, deep experience, high-quality aesthetic feeling, and life advocacy.In terms of the design of creative living goods, Lin Rongtai (2008) divides the added value of the design of creative living goodsinto four stages, namely, added value of science and technology, cultural creativity, aesthetic experience and economic benefits in the middle of the upper half of Figure 1. In terms of service innovation design, each sub-plan is based on this framework, and then cooperates with the goals ofoverall plan to achieve the service innovation design of life creativity, life style, life taste and lifepattern, formingthe results both studied separately and integratedunder common framework, such as the integration of three levels and different stagesin Figure 1.

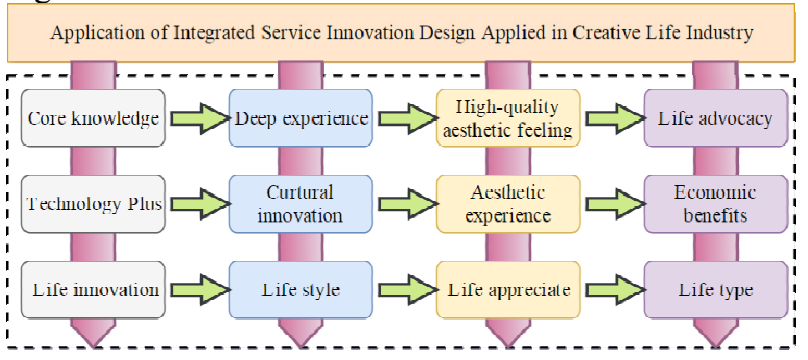

Figure 1. Research framework for integrating creative life industry (Lin Rongtai, 2008)

In order to achieve the purpose of applying service innovation design to creative life industry, this study plans to integrate four assessment dimensions, namely, core knowledge, deep experience, high-quality aesthetic feeling and life advocacy, and discusses the industrial chain of service innovation design through experience design and aesthetic experience. And then according to the concept of design chain, this study introduces the concept of service innovation design into the sustainable management model of creative life industry, that is, combine the creative model of cultural products and the management model of enterprises, as shown in Figure 1. From Figure 1, we can clearly see the vertical integration of the depth of upper, middle and lower reaches of the research plan and the combination of horizontal breadth, which can achieve the goal of sustainable development of creative life industry through transforming the creativity of service innovation into the design ofscientific and technological goods. And then through the horizontal connectionin the research process, each sub-plan has its own research goal, and through the integration of research procedures, the relationship between each other can be formed and the goal of integrated research can be achieved.

According to the above analysis, the creative life industry is based on the integration of culture and aesthetic economy, and it promotes the integration of cultural art and science and technology through the development of life industry, and its actual practice for promotion is to useaesthetic economy to stimulate cross-field industry innovation and achieve the goal of promoting the development of emerging industries.Its 
overall goal is as follows: integrate culture and science and technology and shape Taiwan style; create aesthetic economy and rebuild Taiwanmiracle. And then according to the above framework of aesthetic economy, from the four aspects of culture, science and technology, aesthetics and economy, the four goals of this integrated research plan are as follows:

(1) culture is the life style, and it needs promotion strategy with endless creativity;

(2) science and technology is the life creativity, and it needs pragmatic approach supported by design;

(3) aesthetics is the life taste, and it needs the promotion activities involving the participation of the whole people;

(4) economyis the life pattern, and it needs life concept of the overall construction.

These goals can be two levels: innovation opportunity and entrepreneurial opportunity. In the first level, innovation opportunity formulates and implements specific and effective strategies and measures by aiming at specific key issues in traditional industry, technology industry and design service industry, and enhances the innovative competitiveness of various design industries through life pattern and life creativity by means of culture and technology.In the second level, entrepreneurial opportunity creates life taste and life style in an all-round way by means of aesthetics and economy, and comprehensively promotesand strengthens the design research, design talent training and cross-industry or horizontal alliances to form the creative life industry through the promotion of the aesthetics of the whole people, thus enhancing the overall energy and image of Taiwan's creative life industry.

\section{Case study}

In 1980s, architect Han Baode and the owner of South GardenWang Tiwumet each other, and then a unique garden that combines the characteristics of Jiangnan garden, traditional China and Fujian style building was created, with 27 hectares of boundless green area and valleys hiding in, it is like the pavilion in wonderland, as shown in Figure 2. The original idea of founder Wang is to build a farm as the place for the aged to share family happiness and enjoy nature withtheir relatives and friends.Mr. Han Baodeproposes to build a Jiangnan style garden in accordance with the features of the terrain, because only by creating an independent Paradise can truly wash away the uproar and relax the mind and body.Historical reasonscreate the perceptual field of South Garden, just as the architect of South Garden Han Baode said: "It's hard to imagine the realization of this dream, how fortunate I am to finish it in such a short time,maybe it's a chance that Ji Cheng and Li Yu expect but fail to grasp". (Lin Rongtai, 2010) "The One" is a life style brand established by The One. With the pursuitof "harmonious and happy" life as the goal, a humanistic insistence, a creative viewpoint, and an original thinking, through concrete deduction of design value, are integrated into the objects and fields in life, and play therole of the bridge forfive senses and six feelings of beautiful life. The One believes that design starts from life, and every aspect of life begins with "one", build a day's time, a space, an attitude, and a life. What The One provides is every simple "one", and we can see the obvious life style of The One in every day, every point and every detail of life. The One takes the transfer of oriental aesthetics as its duty, and it is different from the traditional creation concept of totem thinking in the east, and we interpret the new oriental humanistic feelings with simple and gorgeous design style.Simpleness is a choice for extreme simple materials, and also a humanistic persistence with warm meaning; and gorgeousness is a true color inadvertently revealed, and also a spirit of craft carving. We experience the initial and final movement of life between the constringency of simpleness and the luxury of gorgeousness. We show the connotations of qualia goods and pass the life style of The One with the use of extreme simple materials, a humanistic persistence with warm meaning, an oriental freehand aesthetic view, and a spirit of craft carving.

In the early spring of 2007, The One reconstructed the "perceptual field" of South Garden with the spirit of "restoring the old as the old", adhered to the "simple and gorgeous" design aesthetics, selected a lot of materials from South Garden as design elements, and designed the "qualia goods with" life aesthetics; and combined the qualia goodsadvocating simple life and the "perceptual field" with rich cultural deposits to achieve the model of creative life industry. In the mid autumn of 2008, The one Humanistic Leisure Inn of South Garden was opened again to provide five senses and six feelings of new experience for modern gentlemen and beauties.Based on the four functions in Figure 4, this paper studies how The One South Garden buildsthequalia goods into the model of creative life industry through perceptual field.A brief description is as follows:

(1) Field experience (feast eyes): when first come to South Garden, the "ancientry recalling emotion" of Jiangnan garden arouses, after savoring and slow travel, the style combined with the local characteristicsappears indistinctly. When enter wing room, the "simple and gorgeous"design style of The One is shown in the elegance and tranquility, and the simple and low-key designis the best interpretation of "modern fashion". The graceful"modern fashion" is shown in the "ancientry recalling emotion" of Jiangnan garden; the service area of South Garden has made the best use of the virtues of "ancientry recalling emotion" and "modern fashion".

(2) Experience activity (far from uproar): when first come to South Garden, the experience of green bamboo and traildeclares the "far from uproar". The subsequent "green hill, green valley, colorful butterfly, blue magpie and white egret, chirping of cicadas, crowing of birds, croaking of frogs, goose's song and water's sound, after rain, when fog, and under the first sun, the day curtain and the moonlight", are the in-depth experience activities. With the guidance of the artist in the village and the striking charm on the red brick, customers immerse themselves in a zither music situation before dinner, and will have the new experience of human leisure, feel 27 hectares of boundless green area, experience the quiet of 
South Garden, but not see the graceful charm of South Garden, thus the goal of "far from uproar" is achieved.

(3)Cultural connotation (self study): cultural connotation includes formand ritual. The architectural design of South Garden shows the elements of Chinese garden building: pavilion, platform, building, attic, hall, shed, porch, bridge, etc, which are the main forms of garden building, andalso shows the inner symbolic meaning through the ingenious forms. For example, the vaseshaped gate with the shape of vase (form) contains the symbolic meaning of safe come-in and go-out (ritual). The building of South Garden integrates Taiwan's local characteristics such as red brick, red tile, cypress wood, and so on, thus creating a unique garden building and forming another architectural ceremony. The rich cultural deposits of South Garden allow customers to learn various forms and rituals from the experience inthe building of South Garden and understand cultural connotation, thus the effect of "self study" is achieved.

(4) Five-sense experience (entertain oneself as well as others): through the aforementioned qualia goods and customers' experience of five senses and six feelings, The One strengthens the customers'impression on the experience. Taking bambooknown as oriental gentlemanas the design concept, scholars describe bamboo as "sage and gentleman", and the designer turns the image of "bamboo joint" into the dining utensils on the table to praise bamboo's solid root, straight personality, empty heart, chastity, and other characters and sentiments and further present bamboo's simple but elegant, and quiet beauty. Through this kind of qualia goodsfull of senses and feelings, customers are easy to immerse themselves in and re-tell the story of their experience, thus the purpose of "entertaining oneself as well as others" is achieved.

\section{Conclusion}

"Culture" is a kind of life style, "design" is a kind of life taste, "creativity" is a kind of recognition by moving, and "industry' is the medium, means or method to realize cultural design creativity. Therefore, on the cultural level, through cultural creativity, design achieves a kind of design taste and forms a life style through industry. The creative life industry displays the charm of qualia goods through perceptual field, that is, "form products and apply to life". Therefore, the essence of qualia goods is"practical", the result is "pragmatic", and the value is "life oriented".

In terms of perceptual field, design is a cultural creative activity, and its ultimate goal is to form life culture and create perceptual living environment.On the other hand, design is a comprehensive shaping activity with purposes, conditions, rationalization and creativity, and it focuses on the "sociality" of the interaction between "man and objects"; reasonable shaping combining "physical function" and "psychological function" pays attention to "man machine system"and consider "human factor engineering"; finally, the design is integrated into "economic activities" to create "life style", form "life culture", and achieve "perceptual" living environment.

Through the case The One South Garden, this paper discusses how to strengthen and deeply touch consumers through "perceptual field" and "qualia goods", and it just shows the tip of the iceberg of creative life industry, serves as a trigger and provides relevant research reference. The related issues about how to use the cultural deposits of "perceptual field" and "qualia goods" to cultivate cultural value and create economic benefits in the futureshould be further discussed.

\section{References}

1. Baer, D., Wolf, M., \& Risley, R. (1968). Some current dimensions of applied behavior analysis. Journal of Applied Behavior Analysis, 1, 91 - 97.

2. Jackson, R. and Halle, M. (1956). The Fundamentals of Language, The Hague: Mouton.

3. Norman, D. A. (1988). The Psychology of Everyday Things. New York: Basic Boks.

4. Read, H. (1967). Education Through Art. London: Faber and Faber.

5. Read, H. (1967). Education Through Art. London: Faber and Faber.

6. Rubin, J.A. (1984). Child art therapy. New York: Van Nostrand Reinhold.

7. .Lin Rongtai, Sun Mingxian, Tu Liangjin (2008).Exploring Autistic Children's Inner World with Mental Models. The 13th Annual Conference and Symposium of the Design Society of the Republic of China, May 17th, 2008, Chang Gung University. Human Factors Engineering and Cognition, P162.

8. Lin Rongtai, Tu Liangjin, Sun Mingxian, Xie Yicheng, Huang Yuanqing, and Zhang Yaping (2009). The Model of Communication Beyond Language: A Case Study of Autistic Children's Image Communication. International Symposium and Collection of Papers on Special Education and Art psychotherapies, May 30, 2009, National Taizhong University of Education(NTZUE). Children's Art Psychotherapies for Children with Difficulties in Health Care and Emotion, P55. 